\title{
Research on Implementation Performance of Scientific and Technology Insurance Based on the Comprehensive Fuzzy Evaluation
}

\author{
Si-yun $\mathrm{Xu}^{1,2}$, Zheng-Fu ${ }^{3}$ \\ ${ }^{1}$ Department of Insurance, Hebei Finance University, Baoding, China \\ ${ }^{2}$ School of Insurance and Economics, University of International Business and Economics, Beijing, China \\ ${ }^{3}$ Department of Insurance, Hebei Finance University, Baoding, China
}

\begin{abstract}
In the thorough analysis to understand the premise of public governance theory, combined with the actual situation of the science and technology insurance operation, build the evaluation frame of multiple participants, and the evaluation index system is determined. Using comprehensive fuzzy evaluation method, this paper selected the city as empirical research object, to evaluate the effect of science and technology insurance. The results showed that different areas city science and technology insurance coverage and depth difference is obvious.
\end{abstract}

Keywords: Science and technology insurance; Public governance; The comprehensive fuzzy evaluation; The empirical research; Effect evaluation

\section{Introduction}

Main purpose is to prevent the innovation of science and technology insurance risks, so as to improve the initiative of enterprises for independent innovation, promote the further development of enterprise independent innovation ability. Between this, how to scientifically formulate science and technology insurance further deepen internal to the enterprise development strategy and related policy, become the focus of research. In this paper, by means of quantitative analysis, research and analysis of science and technology insurance effect, to discover and reveal the potential of the constraints, and puts forward relative targeted strategies and Suggestions.

Academics on science and technology insurance of positive externalities reached a basic consensus on the issue. However, on how to select method solve the problem of externalities, scholars have different opinions. Kefan Xie, Shi Zhao, Guohua Cao and Yongqing Cai domestic scholars tend to practice the policy of science and technology insurance, also is the way of direct intervention by government departments. In contrast, other scholars more inclined to government departments as the dominant force generated by the commercial mode become dominant in the field of science and technology insurance operation mode.

\section{The mathematical Model}

In real life, many practical problems are very complicated, for these problems and establish the system of evaluation, some index properties when measurement uncertainty is greatly, the uncertainty is plagued by more and more researchers and evaluators to study the recognition and evaluation. So choose reasonable evaluation method is particularly important.

\subsection{Evaluation method}

Analytic hierarchy process (AHP) to the problem of fuzzy processing result is not ideal. It is difficult accurate evaluation results. And fuzzy comprehensive evaluation is one of the basic methods of system evaluation analysis, this 
model has been widely used, especially in the field of has the very good application prospect of soft science, the comprehensive fuzzy evaluation has been proved that the application of it can bring good economic and social benefits. So this article will be comprehensive fuzzy evaluation and AHP analysis combined with quantitative analysis. Because the AHP is a common method, the paper only explains the comprehensive fuzzy evaluation.

\subsection{The comprehensive fuzzy evaluation method and its mathematical model}

The so-called comprehensive fuzzy evaluation is in the complex social environment, problems in fuzzy conditions, considering the influence of many factors, in order to achieve a certain use value to achieve the purpose of which to a certain things or problems to make comprehensive evaluation method.

The multilevel model is one kind of the comprehensive fuzzy evaluation. We will explant this model in the following content.

For some complex problems, it needs to consider the very complex factors. At this time problems and questions often has two ways, one is at this point difficult to determine the weight coefficient distribution of these complicated factors, on the other hand, even after trying to determine the weight coefficient distribution of these factors. But due to the need to consider the consistency of judgments matrix, the normalization conditions lead to each factor weight get smaller. Through Zadeh comprehensive evaluation, the value of the result often becomes smaller than before. At this time to hierarchical division of factor set, fuzzy evaluation model of the above steadily expands into a multi-level fuzzy comprehensive evaluation mathematical model. Mathematical model of expansion is in the initial model application on the basis of the original factors of multilayer division, at this time a level of evaluation on input from one level of the evaluation results, starting from the bottom. Until it reaches the top shall be terminated. If the number of divisions of numerical, $\mathrm{U}=\left\{\mathrm{u}_{1}, \mathrm{u}_{2}, \cdots \cdots, \mathrm{u}_{\mathrm{n}}\right\}$ will be a factor set, then got the mathematical model with two layers that belongs to the fuzzy comprehensive evaluation model. The specific formula is as follows:

$\mathrm{B}_{\mathrm{T} 0}=A \circ S=A \circ\left[\begin{array}{l}A_{1} \circ S_{1} \\ A_{2} \circ S_{2} \\ \vdots \\ A_{n} \circ S_{n}\end{array}\right]$

Type of matrix A, on behalf of the weight distribution coefficient and collection, specifically its set, $U / s=\left\{u_{i 1}, u_{i 2}, \cdots \cdots, u_{i k}\right\}$ of $\mathrm{n}$ factors weight distribution; $A_{i}$ is said a certain factor weight coefficient distribution, $U_{i}=\left\{u_{i 1}, u_{i 2}, \cdots \cdots, u_{i k}\right\}$ namely in the collection corresponding to factor weight distribution;

$\mathrm{S}$ and $\mathrm{S}_{\mathrm{i}}$ - comprehensive judgment matrix, respectively, that is $U_{i}$, set $U / S$ with the comprehensive judgment of transform matrix;

$B_{\mathrm{T} 0}-$ Representing a collection of $\mathrm{U} / \mathrm{s}$ for the factor sets produced by the ultimate need of comprehensive evaluation results.

If you want to get more detailed layered, only will have the points set U/s doing the above work is divided, get comprehensive evaluation model of three layers. If you continue, you will have four or more levels of comprehensive evaluation model.

\section{The establishment of the index system}

\subsection{Evaluation Perspective}

From the perspective of the development of the insurance industry, especially the development of some mandatory coverage, the insurance operation performance is related to many subjects. As a member of the types of insurance, insurance is likelihood of science and technology. Therefore, if you want a science and technology insurance effect is relatively scientific evaluation, we should be based on the multiple players, standing on the perspective of 
multi-agent, construct evaluation system, the performance of integrated fuzzy evaluation.

\subsection{Evaluation system}

In this paper, according to participate in order to build evaluation system.

The first is the supply side of science and technology insurance and the insurance company. Insurance companies provide science and technology of insurance coverage. From the point of view of implementation effect and the insurance company to has a role in three aspects for implementation. Respectively is: the degree of product innovation can develop with innovation characteristics are planted is the decisive factor for effect. Out the claim amount, this is related to their own interests in mind, science and Technology Company for insurance. Settling time, the key lies in the influence of science and technology enterprise ginseng protect enthusiasm.

For the demand side, science and technology enterprises, it is the purpose of ginseng is to guard against enterprise innovation risk. The practicability of technology companies place more insurance.

Nowadays, the social from all walks of life need to third party involvement of power, to ensure the coordination between different sectors and to promote the new system, the implementation of related regulations and measures. Among them, the government plays an important role. It is the only one can make use of coercive power to promote and guide the social resources and standardize enterprise behavior effectively, and maintain social justice organizations. In addition, is the involvement of the third party to participate in, the purpose is to regulate the behavior of insurance company's related basic interests protection ginseng company, is to provide security for the insurance company, as far as possible to reduce the insurance company due to information asymmetry cause of adverse problems.

With the above analysis can be concluded that the evaluation index system, the concrete are shown in table 1 below.
Table.1 the evaluation index system

\begin{tabular}{|c|c|c|}
\hline $\begin{array}{c}\text { Target } \\
\text { layer }\end{array}$ & $1^{\text {st }}$ indicator & $2^{\text {nd }}$ indicator \\
\hline \multirow{9}{*}{ 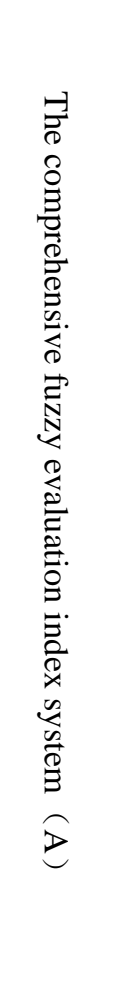 } & \multirow{3}{*}{$\begin{array}{c}\text { The insurance } \\
\text { company } \\
\text { A1 }\end{array}$} & $\begin{array}{l}\text { Product innovativeness } \\
\text { A11 }\end{array}$ \\
\hline & & $\begin{array}{c}\text { Claim amount } \\
\text { A12 }\end{array}$ \\
\hline & & $\begin{array}{c}\text { Settlement of claims } \\
\text { A13 }\end{array}$ \\
\hline & \multirow{3}{*}{$\begin{array}{l}\text { The technology } \\
\text { company } \\
\text { A2 }\end{array}$} & The proportion A21 \\
\hline & & Insured amounts A22 \\
\hline & & $\begin{array}{c}\text { Insurance } \\
\text { compensation ratio A23 }\end{array}$ \\
\hline & \multirow{3}{*}{$\begin{array}{c}\text { The social third } \\
\text { party } \\
\text { A3 }\end{array}$} & $\begin{array}{c}\text { Government support } \\
\text { A31 }\end{array}$ \\
\hline & & $\begin{array}{c}\text { Insurance brokerage } \\
\text { company involvement } \\
\text { A32 }\end{array}$ \\
\hline & & $\begin{array}{c}\text { Industry association } \\
\text { degree of intervention } \\
\text { A33 }\end{array}$ \\
\hline
\end{tabular}

\section{Effect evaluation analysis}

\subsection{The Data Processing}

This article takes the letter consultation and field interview two ways to collect data. To reduce the cognitive difference between different areas, the paper subjects to produce the difference. The objects are mainly concentrated in Beijing(B), Shanghai(SH), Shenzhen(SZ), and Tianjin(TJ). Company chose four of the city a total of, and data collection is complete, higher credibility.

When the data collection was finished, the next job is dimensionless processing of statistical data according to the basic requirements.

\subsection{The Case Analysis}

A comprehensive fuzzy evaluation index evaluation system is built. Because of, not only is a quantitative indicator into the indicator evaluation system, there are quite a number of qualitative indicators. So we adopt the way of expert 
scoring, determine the index weight at all levels, at the same time consistency inspection, to ensure that the indicators in line with the basic requirements of the model.

Consistency check finished, use the constructed model for further analysis. We can get the result of comprehensive evaluation, as shown in table 2 .

Table. 2 the Comprehensive Evaluation of the Results

\begin{tabular}{|c|c|c|c|c|}
\hline Type & BJ & SH & SZ & TJ \\
\hline A1 & 37.08 & 43.80 & 57.43 & 30.56 \\
\hline A2 & 89.99 & 20.12 & 70.45 & 30.81 \\
\hline A3 & 79.56 & 32.43 & 23.98 & 43.76 \\
\hline $\begin{array}{c}\text { Compo } \\
\text { site } \\
\text { scores }\end{array}$ & 74.12 & 47.21 & 58.62 & 53.89 \\
\hline
\end{tabular}

\section{Conclusion}

In the thorough analysis to understand the premise of public governance theory and combined with the actual situation of the science and technology insurance operations, the paper builds evaluation framework of the selection and determine a set of comprehensive evaluation index system for quantitative analysis of the science and technology insurance, including of the technology innovative enterprise, insurance companies, the state administrative service department and the social supervision, inspection. Using comprehensive fuzzy evaluation method, this paper selected the four location areas, not the same city, as empirical research object, to evaluate the effect of science and technology insurance.
The results showed that different areas city science and technology insurance coverage and depth difference is obvious.

\section{Acknowledgements}

The research work was supported by 2014 Annual Research Fund Project of HeBei Finance University under Grant NO.JY201406 and Baoding city Science and Technology Bureau under Grant No. 15ZR017.

\section{Reference}

[1] Xueqing Shao, Zhichun Liu, "Design the framework of policy science and technology insurance," Proc. China Venture Capital, pp. 49-52, 2007.

[2] Kefan Xie, Ye Liu, "In the implementation of science and technology insurance three incomplete information dynamic game analysis," Proc. China Venture Capital, pp. 6-9, 2009.

[3] Gang Zhao, Jinghui Zhao, "Problems and countermeasures in the development of insurance of our country science and technology," Proc. Journal of Wuhan University of Technology (Social Science Edition), pp. 24-27, 2011.

[4] Yang Zhao, Wendong Lv, "Science and technology insurance pilot status, problems and countermeasures in three years ," Proc. Scientific decision-making, pp. 1-24, 2011. 